\title{
ANALISIS FAKTOR-FAKTOR YANG MEMPENGARUHI OBESITAS \\ PADA ORANG DENGAN DISABILITAS INTELEKTUAL : A LITERATURE REVIEW
}

\section{ANALYSIS OF FACTORS AFFECTING OBESITY IN PEOPLE WITH INTELLECTUAL DISABILITY: A Literature Review}

\author{
Erviana $^{1}$, Titiek Hidayati ${ }^{2}$ \\ Master of Nursing Faculty of Medicine and Health Sciences ${ }^{1}$, Lecture In \\ Medical Study Program Dept Of Epidemology Of Family Medicine \\ Community Health ${ }^{2}$ Universitas Muhammadiyah Yogyakarta, Ring Road \\ Selatan, Bantul,Yogyakarta \\ (Erviana.evvi@yahoo.com, hidayatifkumy@yahoo.co.id)
}

\begin{abstract}
ABSTRAK
Latar Belakang : Tahun 2016 lebih dari 1,9 miliar orang dewasa berusia 18 tahun ke atas mengalami kelebihan berat badan. Lebih dari 650 juta orang dewasa mengalami obesitas. Secara keseluruhan, sekitar $13 \%$ dari populasi orang dewasa di dunia mengalami obesitas pada tahun 2016. Prevalensi obesitas di seluruh dunia hampir tiga kali lipat antara tahun 1975 dan 2016. Pada 2016, diperkirakan 41 juta anak di bawah usia 5 tahun kelebihan berat badan atau obesitas dan lebih dari 340 juta anak-anak dan remaja berusia 5-19 kelebihan berat badan atau obesitas. Prevalensi kejadian obesitas lebih tinggi pada orang dengan kecacatan intelektual daripada populasi pada umumnya.

Tujuan : Untuk mengetahui faktor-faktor yang menyebabkan obesitas pada orang dengan disabilitas intelektual.

Metode : Database kesehatan yang relevan termasuk EBSCO, PUBMED, Proquest dan Scholar dicari dengan menggunakan kombinasi tema : intellectual disability,obesity, adults, dan young people.

Hasil : Berdasarkan hasil review artikel faktor-faktor yang mempengaruhi obesitas pada orang dengan disabilitas intelektual adalah kemiskinan,aktivitas fisik, alkohol, kebiasaan diet, lingkungan tempat tinggal, penggunaan obat, jenis kelamin, usia, pendidikan orang tua, down syndrom.

Simpulan : Faktor- faktor yang menyebabkan obesitas pada orang disabilitas intelektual adalah diet, aktivitas fisik, kemiskinan, alkohol, lingkungan tempat tinggal, penggunaan obat, jenis kelamin, usia, pendidikan orang tua dan down syndrome.
\end{abstract}

Kata Kunci : Disabilitas intelektual, obesitas

\section{ABSTRACT}

Background : In 2016 more than 1.9 billion adults aged 18 years and over were overweight. More than 650 million adults are obese. Overall, around $13 \%$ of the world's adult population is obese in 2016. The prevalence of obesity worldwide 
has nearly tripled between 1975 and 2016. In 2016, an estimated 41 million children under 5 years were overweight or obese and more than 340 million children and adolescents aged 5-19 were overweight or obese. The prevalence of obesity is higher in people with intellectual disabilities than the general population.

Purpose : Purpose this study was to determine factors that cause obesity in people with intellectual disabilities.

Methods : Relevant health databases including EBSCO, PUBMED, Proquest and Scholar are sought using a combination of themes: intellectual disability, obesity, adults, and young people.

Results : Based on the results of the article review the factors that influence obesity in people with intellectual disabilities are poverty, physical activity, alcohol, dietary habits, living environment, drug use, gender, age, parental education, down syndrome

Conclusion :Tthe factors that cause obesity in people with intellectual disabilities are diet, physical activity, poverty, alcohol, living enviroment, drug use, gender, age, parental education and down syndrome.

Keywords : Intellectual disability, obesity

\section{PENDAHULUAN}

International Classification of Functioning, Disability and Health (ICF) mendefinisikan kecacatan (disabilitas) sebagai istilah umum untuk gangguan, pembatasan aktivitas dan pembatasan partisipasi. Kategori disabilitas meliputi disabilitas sensori, neurologis, fisik, intelektual, kognitif dan psikiatri (Ginsburg \& Rapp, 2013). Disabilitas menyebabkan seorang individu mudah mengalami penurunan kesehatan, bermasalah dengan pribadi sendiri (sikap negatif), dan lingkungan (dukungan sosial terbatas dan transportasi yang sulit diakses). Lebih dari satu miliar orang diperkirakan hidup dengan berbagai jenis kecacatan. Terdapat sekitar $15 \%$ populasi dunia yaitu 110 juta $(2,2 \%)$ dan 190 juta $(3,8 \%)$ orang berusia 15 tahun ke atas memiliki kesulitan dalam melakukan fungsinya (WHO, 2016).

Orang-orang penyandang disabilitas sangat rentan terhadap kekurangan layanan perawatan kesehatan. Bergantung pada kelompok dan tempat, orangorang penyandang cacat dapat mengalami kerentanan yang lebih besar terhadap kondisi sekunder, kondisi yang tidak wajar, kondisi terkait usia, terlibat dalam perilaku berisiko kesehatan dan tingkat kematian dini yang lebih tinggi. Beberapa penelitian telah menunjukkan bahwa orang-orang. Permasalahan yang mengenai penyandang disabilitas salahsatu diantaranya adalah obesitas. Jurnal yang dikemukan oleh Martines Fermin Z, Campillo Jose M M, Ato Manuel G pada tahun 2014 mengatakan bahwa obesitas saat ini menjadi masalah kesehatan utama di masyarakat maju, prevalensinya meningkat di seluruh dunia dan itu merupakan faktor risiko tinggi untuk penyakit tidak menular (WHO , 2014). 
Obesitas adalah suatu keadaan terjadinya penimbunan lemak yang berlebihan di dalam tubuh. Pada umumnya obesitas merupakan faktor risiko untuk terjadinya berbagai jenis penyakit degeneratif, seperti diabetes melitus, hipertensi, penyakit jantung koroner dan berbagai jenis kanker (Mahan et al, 2012). Obesitas tidak hanya terkait dengan masalah kesehatan yang dapat menyebabkan diabetes, hipertensi, penyakit kardiovaskuler dan kematian dini, tetapi juga terkait dengan masalah psikososial dan beban sosial ekonomi (Finkelstein et al 2003, 2010;.Dixon 2010). Perkembangan tren obesitas akan menyebabkan beban ekonomi pada masyarakat (Wang et al. 2008 ; Hsieh K et al, 2013).

Pada tahun 2016, lebih dari 1,9 miliar orang dewasa berusia 18 tahun ke atas mengalami kelebihan berat badan. Dari jumlah tersebut, lebih dari 650 juta orang dewasa mengalami obesitas. Secara keseluruhan, sekitar $13 \%$ dari populasi orang dewasa di dunia mengalami obesitas pada tahun 2016. Prevalensi obesitas di seluruh dunia hampir tiga kali lipat antara tahun 1975 dan 2016. Pada 2016, diperkirakan 41 juta anak di bawah usia 5 tahun kelebihan berat badan atau obesitas dan lebih dari 340 juta anak-anak dan remaja berusia 5-19 kelebihan berat badan atau obesitas. Tren masalah obesitas telah bergeser dari yang sebelumnya terjadi pada negara-negara berpenghasilan tinggi yang sekarang meningkat pada negara-negara berpenghasilan rendah. Kegemukan dan obesitas dikaitkan dengan lebih banyak kematian di seluruh dunia daripada kekurangan berat badan. Secara global ada lebih banyak orang yang mengalami obesitas daripada kekurangan berat badan - ini terjadi di setiap wilayah kecuali bagian Afrika sub-Sahara dan Asia ( WHO, 2018 )

Jurnal D. Gazizova et al ( 2012 ) mengatakan bahwa prevalensi obesitas lebih tinggi pada orang dengan kecacatan intelektual daripada populasi pada umumnya (Janicki et al 2002;. Hove 2004). Hal ini juga sejalan dengan salah satu penelitian yang mengatakan bahwa ada kecenderungan peningkatan prevalensi kelebihan berat badan pada orang dewasa dengan cacat intelektual (Yamaki 2005). Pada orang dengan cacat intelektual peningkatan obesitas merupakan sebuah ketimpangan kesehatan (Emerson \& Hatton 2014; Taggart \& Cousins 2014). Akuisisi dan pelaksanaan pemberian promosi kesehatan terhalang karena kognitif, sosial dan perilaku yang membentuk disesuaikan dengan perilaku pada orang dengan cacat intelektual seperti pengendalian diri, penetapan tujuan, keterampilan yang berhubungan dengan perawatan kesehatan di rumah, persepsi risiko dan perencanaan eksekutif secara definisi (AAIDD 2010) secara signifikan terbatas pada orang dengan cacat intelektual.

\section{METODE PENELITIAN}

Tujuan dari artikel ini adalah untuk mereview faktor-faktor yang mempengaruhi obesitas pada orang dengan cacat intelektual. Metode yang digunakan dalam penulisan artikel ini adalah literatur review. Literatue review adalah sebuah pencarian literatur yang menggunakan database kesehatan yang 
relevan termasuk EBSCO, PUBMED, Proquest dan Scholar dicari dengan menggunakan kombinasi istilah pencarian : intellectual disability,obesity, Adulst dan young people. Pencarian artikel menggunakan kriteria inklusi yaitu penelitian harus berkaitan dengan obesitas dan disabilitas intelektual, penelitian harus memberikan informasi tentang hal-hal yang mempengaruhi obesitas pada orang dengan disabilitas intelektual dan teks lengkap studi harus tersedia dalam bahasa Inggris. Kriteria eksklusi yang digunakan yaitu Publikasi tidak asli seperti surat ke editor, abstrak saja, dan editorial.

\section{HASIL DAN PEMBAHASAN}

\section{Tabel 1. Proses Pencarian Artikel}

\begin{tabular}{cl}
\hline Data base & \multicolumn{1}{c}{ Hasil pencarian } \\
\hline EBSCO & 2682 Artikel di didentifikasi berdasarkan tema pencarian Intellektual \\
& disabilty, ketika tema pencarian di tambah dengan obesity and adults \\
& ditemukan menjadi 28 jurnal. 13 jurnal dinilai berdasarkan kelayakan \\
& abstrak dan terpilih menjadi 3 setelah diseleksi untuk di review dalam \\
& literatur review ini. \\
& The article was identified based on the Intellectual disabilty search theme, \\
& when the search theme added with obesity and adults was found to be 20 \\
Proquest & journals. 5 journals were assessed on the basis of abstract eligibility and \\
& were selected 1 after being selected for review in this review literature. \\
& 16800 Artikel di didentifikasi berdasarkan tema pencarian Intellektual \\
& disabilty, ketika tema pencarian di tambah dengan obesity and adults \\
& ditemukan menjadi 1700 jurnal. 21 jurnal dinilai berdasarkan kelayakan \\
& abstrak dan terpilih menjadi 2 setelah diseleksi untuk di review dalam \\
& literatur review ini.
\end{tabular}

\section{Tabel 2. Studi Karakteristik}

\begin{tabular}{|c|c|c|c|c|c|c|}
\hline $\begin{array}{l}\text { Author } \\
\text { ( year ) }\end{array}$ & Title & source & Tujuan & Design & sampel & $\begin{array}{c}\text { Risk Faktor / } \\
\text { Hasil } \\
\end{array}$ \\
\hline $\begin{array}{c}\text { (Robertso } \\
\text { n, } \\
\text { Emerson, } \\
\text { Baines, \& } \\
\text { Hatton, } \\
\text { 2014) }\end{array}$ & $\begin{array}{l}\text { Obesity and } \\
\text { health } \\
\text { behaviours of } \\
\text { British adults } \\
\text { with self- } \\
\text { reported } \\
\text { intellectual } \\
\text { impairments : } \\
\text { cross sectional } \\
\text { survey }\end{array}$ & Proquest & $\begin{array}{l}\text { Untuk } \\
\text { mengetahui } \\
\text { tingkat } \\
\text { obesitas dan } \\
\text { perilaku } \\
\text { kesehatan } \\
\text { pada orang } \\
\text { dewasa } \\
\text { inggris } \\
\text { dengan } \\
\text { kecacatan } \\
\text { intelektual }\end{array}$ & $\begin{array}{l}\text { Crossecti } \\
\text { onal } \\
\text { study }\end{array}$ & $\begin{array}{l}\text { Pada } \\
\text { gelombang } \\
1 \text { sebesar } \\
50994 \\
\text { peserta dan } \\
54.585 \\
\text { peserta } \\
\text { pada } \\
\text { gelombang } \\
2 .\end{array}$ & $\begin{array}{lr}\text { Kemiskinan, } & \text { tidak } \\
\text { aktif } & \text { (kurang } \\
\text { aktivitas } & \\
\text { pengggunaan } & \\
\text { tembakau } & \text { dan } \\
\text { alkohol bagi pria } \\
\text { dengan } \\
\text { intelectual. }\end{array}$ \\
\hline $\begin{array}{c}\text { (Koritsas } \\
\text { \& Iacono, } \\
2016)\end{array}$ & $\begin{array}{l}\text { Weight, } \\
\text { nutrition, food } \\
\text { choice, and } \\
\text { physical } \\
\text { activity } \\
\text { inadults with } \\
\text { intellectual } \\
\text { disability }\end{array}$ & EBSCO & $\begin{array}{l}\text { Untuk } \\
\text { menggambar } \\
\text { kan nutrisi, } \\
\text { pilihan } \\
\text { makanan } \\
\text { dan status } \\
\text { berat badan } \\
\text { pada orang }\end{array}$ & $\begin{array}{l}\text { Crossecti } \\
\text { onal } \\
\text { study }\end{array}$ & $\begin{array}{l}\text { Dalam } \\
\text { penelitian } \\
\text { ini } \\
\text { awalnya } \\
\text { terdapat } 96 \\
\text { sampel } \\
\text { namun } \\
\text { hanya } 89\end{array}$ & $\begin{array}{lr}\text { Kebiasaan } & \text { diet } \\
\text { (komsumsi } & \\
\text { minuman } & \text { bersoda), } \\
\text { aktivitas } & \text { fisik } \\
\text { (kurang aktivitas), } \\
\text { tinggal } & \text { dengan } \\
\text { orang } & \text { lain, } \\
\text { penggunaan } & \text { obat }\end{array}$ \\
\hline
\end{tabular}




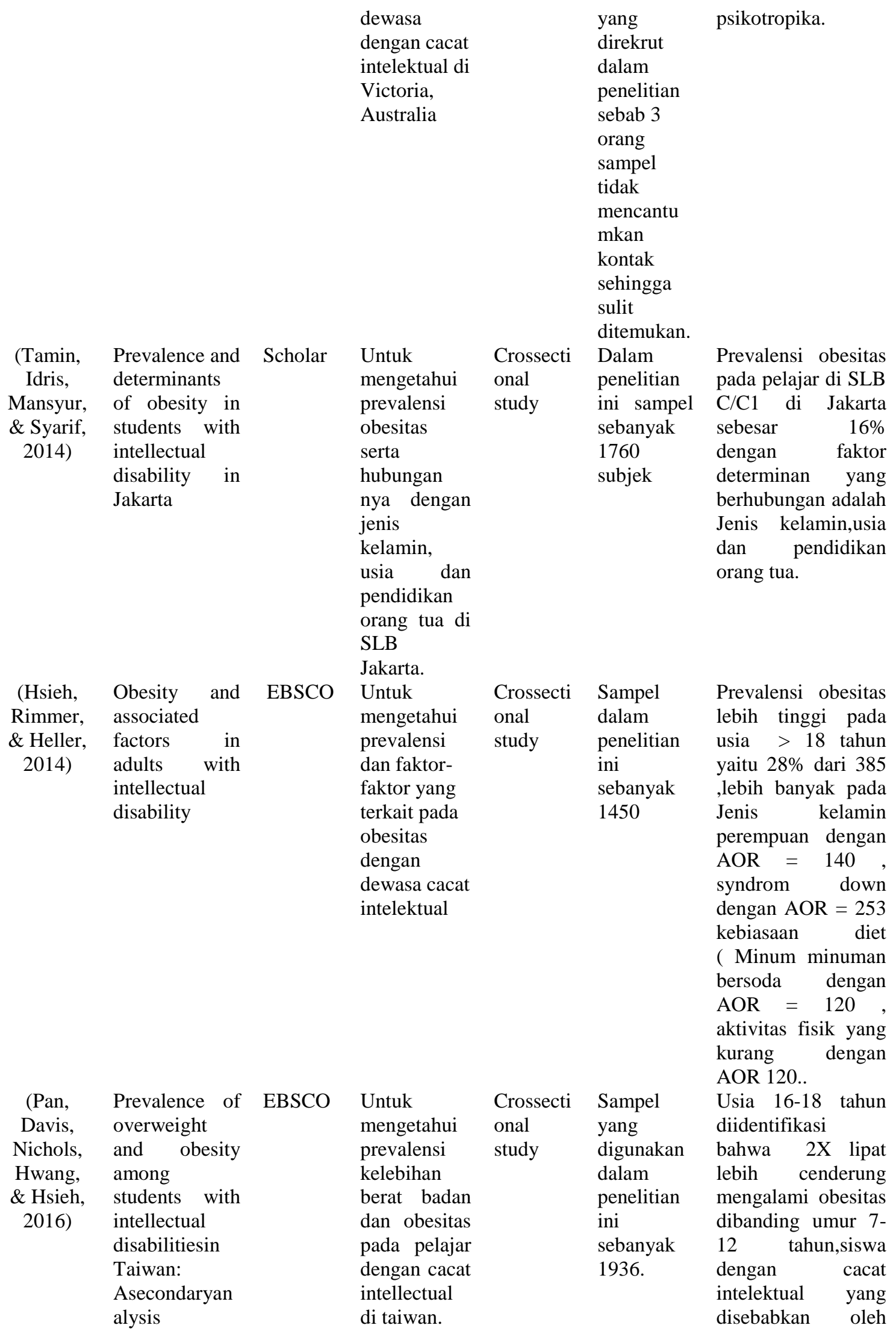




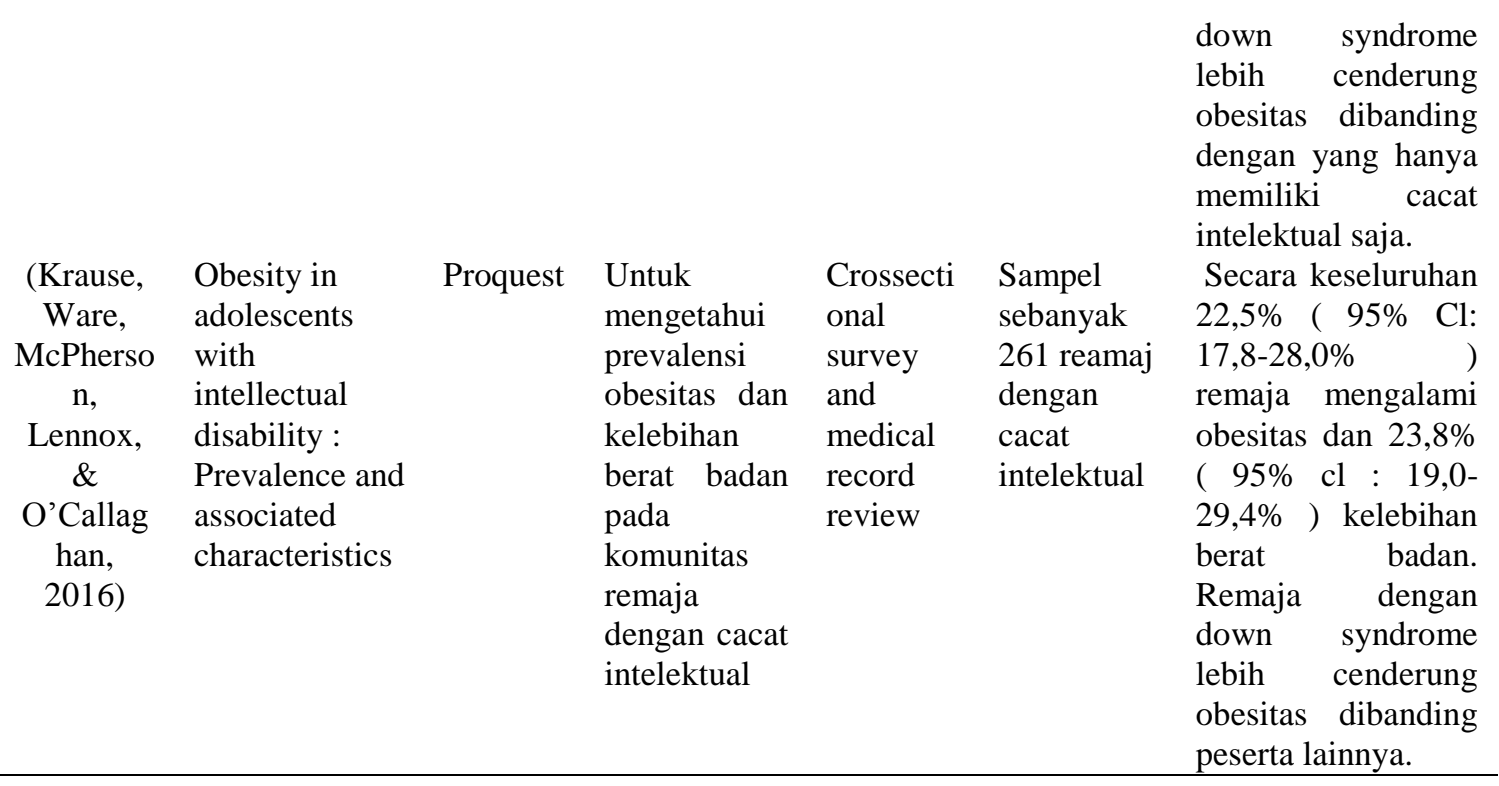

Berdasarkan 6 artikel yang telah direview 6 artikel tersebut menggunakan metodologi penelitian crossectional study dengan lama penelitian yang bervariasi. Hasil review yaitu faktor yang berkaitan dengan terjadinya obesitas pada orang dengan kecacatan intelektual adalah kemiskinan ( Robertson, Emerson, Baines, \& Hatton, 2014), aktivitas fisik (Robertson, Emerson, Baines, \& Hatton, 2014 ; Koritsas \& Iacono, 2016 ; Hsieh, Rimmer, \& Heller, 2014 ; Krause, Ware, McPherson, Lennox, \& O'Callaghan, 2016) , alkohol (Robertson, Emerson, Baines, \& Hatton, 2014) , kebiasaan diet (Koritsas \& Iacono, 2016 ; Hsieh, Rimmer, \& Heller, 2014), lingkungan tempat tinggal (Koritsas \& Iacono, 2016 ), penggunaan obat, jenis kelamin, usia, pendidikan orang tua (Tamin, Idris, Mansyur, \& Syarif, 2014)dan down syndrome ( Krause, Ware, McPherson, Lennox, \& O'Callaghan, 2016).

1. Aktivitas Fisik

Setiap jurnal yang telah di review mengatakan bahwa adalah aktivitas fisik sebagai salahsatu faktor yang berpengaruh pada kejadian obesitas. Dalam jurnal Koritsas \& Iacono ( 2016 ) dikatakan bahwa dibandingkan dengan populasi pada umumya, lebih sedikit orang yang dengan cacat intelektual memenuhi rekomendasi aktivitas fisik ( Robertson et al 2000 ; Temple et al 2000 ; Temple \& Walkley 2003 ; Finlayson et al 011 ), padahal intensitas dan frekuensi aktivitas fisik yang sesuai dapat mengurangi resiko penyakit jantung koroner, stroke, osteoporosis, kanker usus besar, osteoartrhitis, nyeri punggung bawah dan meningkatkan kesehatan mental (Warburton, et al 2006).

2. Alkohol

Penggunaan alkohol dilaporkan bahwa penggunaan alkohol dikalangan cacat intelektual memang lebih sedikit dibandingkan dengan populasi pada umumya. Namun ditemukan bahwa tingkat merokok jauh lebih banyak dikalangan remaja dengan cacat intelektual ringan. Secara signifikan 
komsumsi alkohol dan tembakau tidak lebih besar bagi perempuan namun sebaliknya pada laki-laki (Robertson et al, 2014).

3. Lingkungan Tempat Tinggal

Lingkungan tempat tinggal, dijelaskan bahwa lingkungan tempat tinggal yang dimaksudkan disini adalah bagaimana dan dengan siapa orang dengan cacat intelektual tersebut tinggal, apakah bersama keluarga, tinggal sendiri ataupun tinggal di lingkungan rumah asuh. Prevalensi untuk obesitas ditemukan bahwa orang yang tinggal sendiri lebih cenderung untuk mengalami obesitas dibandingkan dengan orang yang tempat tinggalnya bersama keluarga ataupun tinggal di rumah asuh ( Koritsas \& Iacono, 2016 ; Hsieh, Rimmer, \& Heller, 2014). Hal ini dimaksudkan karena bagaimanapun orang yang tempat tinggalnya bersama dengan keluarga ataupun di tempat asuh memiliki pengaturan makanan yang lebih ketat, maksudnya dalam hal pola makan dan yang lainnya dapat di kontrol oleh orang lain yang tinggal dengannya dibandingkan dengan tinggal sendiri Bhaumik et al ( 2008 ) dalam Koritsas \& Iacono ( 2016 ).

4. Penggunaan Obat-obatan

Penggunaan obat juga merupakan salah satu faktor yang berkaitan dengan kejadian obseitas yang dibahas dalam beberapa jurnal. Dikatakan dalam jurnal Koritsas \& Iacono ( 2016 ) bahwa penggunaan obat seperti psikotropika yang digunakan sebagai obat antidepresan dan juga obat tidur. Penggunaan berkepanjangan obat ini telah dikaitkan dengan penambahan berat badan dan obesitas pada populasi umum ( Taylor et al 2000 ; malhi et al 2001 ).

5. Jenis Kelamin

Prevalensi kejadian obesitas dikalangan wanita lebih banyak dibandingkan prevalensi dari laki- laki ( Hsieh, Rimmer, \& Heller, 2014 ). Namun berbeda dengan penelitian yang dilakukan oleh penelitian yang dilakukan oleh (Tamin, Idris, Mansyur, \& Syarif, 2014) yang menemukan bahwa prevalensi obesitas lebih tinggi dikalangan pria daripada wanita.

6. Pendidikan orang tua

Berdasarkan tingkat pendidikan orang tua, ditemukan bahwa prevalensi obesitas yang tertinggi yaitu pada orang tua yang memiliki tingkat pendidikan orang tua yang tinggi. Pendidikan orang tua yang tinggi akan meningkatkan status sosial ekonomi keluarga sehingga akan meningkatkan kemampuan keluarga mengkomsumsi lebih banyak makanan (Tamin, Idris, Mansyur, \& Syarif, 2014). Hal ini tentunya bertolak belakang dengan salah satu penelitian yang mengatakan bahwa kemiskinan menjadi salah satu faktor yang dibahas dalam terjadinya obesitas pada remaja atau dewasa dengan cacat intelektual karena kelebihan nutrisi telah diamati di negara-negara berkembang dan telah dikaitkan dengan perubahan yang cepat dalam diet yang dihasilkan dari modernisasi dan globalisasi pasar dimana makanan cepat saji terjangkau dan outlet yang menjual makanan padat dan berenergi murah tetapi tidak mengandung gizi seimbang banyak tersedia ( Hsieh, Rimmer, \& Heller, 2014).

Ketidaksetaraan kesehatan yang dialami oleh orang-orang dengan cacat intelektual disebabkan karena kondisi mereka yang miskin jika dikaitkan dengan sosial ekonomi ( Robertson, Emerson, Baines, \& Hatton, 2014). 
Artikel yang direview menjelaskan bahwa faktor-faktor tersebut berpengaruh dalam kejadian obesitas namun secara pasti tidak diuraikan secara mendalam mengenai faktor-faktor tersebut. Misalnya saja dalam beberapa jurnal dikatakan bahwa obat-obatan seperti psikotropika mempengaruhi kejadian obesitas tetapi jenis obat dan bagaimana kaitannya dengan obesitas tidak dijelaskan secara pasti. Dalam setiap literatur yang direview faktor yang paling sering muncul berpengaruh terhadap obesitas adalah kurangnya aktivitas fisik dan hanya ada satu jurnal yang membahas tentang kemiskinan sebagai salah satu faktor yang berpengaruh terhadap obesita pada remaja atau dewasa dengan cacat intelektual.

\section{SIMPULAN DAN SARAN}

\section{Simpulan}

Tinjauan dalam literatur review penelitian ini mendapatkan hasil bahwa ada beberapa faktor yang mempengaruhi kejadian obesitas pada orang dengan disabilitas intelektual diantaranya adalah kemiskinan,aktivitas fisik, alkohol, kebiasaan diet, lingkungan tempat tinggal, penggunaan obat, jenis kelamin, usia, pendidikan orang tua, down syndrom. Namun tidak menutup kemungkinan akan lebih banyak faktor lain lagi yang terkait sebab beberapa keterbatasan yang dialami oleh para peneliti dalam ke enam jurnal yaitu keterbatasan berkomunikasi dengan responden yang memiliki kecacatan intelektual.

\section{Saran}

Saran bagi peneliti selanjutnya yaitu diharapkan dapat melakukan penelitian lebih lanjut mengenai faktor-faktor yang mempengaruhi kejadian obesitas pada orang dengan cacat intelektual.

\section{DAFTAR PUSTAKA}

Gazizova, D., Puri, B. K., Singh, I., \& Dhaliwal, R. (2012). The overweight: Obesity and plasma lipids in adults with intellectual disability and mental illness. Journal of Intellectual Disability Research, 56(9), 895-901. https://doi.org/10.1111/j.1365-2788.2011.01468.x

Hsieh, K., Rimmer, J. H., \& Heller, T. (2014). Obesity and associated factors in adults with intellectual disability. Journal of Intellectual Disability Research, 58(9), 851-863. https://doi.org/10.1111/jir.12100

Koritsas, S., \& Iacono, T. (2016). Weight, nutrition, food choice, and physical activity in adults with intellectual disability. Journal of Intellectual Disability Research, 60(4), 355-364. https://doi.org/10.1111/jir.12254

Krause, S., Ware, R., McPherson, L., Lennox, N., \& O’Callaghan, M. (2016). Obesity in adolescents with intellectual disability: Prevalence and associated characteristics. Obesity Research \& Clinical Practice, 10(5), 520-530. https://doi.org/10.1016/j.orcp.2015.10.006

Maneval, R., Fowler, K. A., Kays, J. A., Boyd, T. M., Shuey, J., Harne-Britner, S., \& Mastrine, C. (2012). The Effect of High-Fidelity Patient Simulation on 
the Critical Thinking and Clinical Decision-Making Skills of New Graduate Nurses. The Journal of Continuing Education in Nursing, 43(3), 125-134. https://doi.org/10.3928/00220124-20111101-02

Martínez- Zaragoza, F., Campillo- Martínez, J. M., Ato- García, M., MartínezZaragoza, F., Campillo-Martínez, J. M., Ato-García, M., ... Ato García, M. (2016). Effects on physical health of a multicomponent programme for overweight and obesity for adults with intellectual disabilities. Journal of Applied Research in Intellectual Disabilities, 29(3), 250-265. https://doi.org/10.1111/jar.12177

Pan, C.-C., Davis, R., Nichols, D., Hwang, S. H., \& Hsieh, K. (2016). Prevalence of overweight and obesity among students with intellectual disabilities in Taiwan: A secondary analysis. Research in Developmental Disabilities, 5354, 305-313. https://doi.org/10.1016/j.ridd.2016.02.018

Robertson, J., Emerson, E., Baines, S., \& Hatton, C. (2014). Obesity and health behaviours of British adults with self-reported intellectual impairments: cross sectional survey. BMC Public Health, 14(1), 219. https://doi.org/10.1186/1471-2458-14-219

Tamin, T. Z., Idris, F. H., Mansyur, M., \& Syarif, D. R. (2014). Prevalence and determinants of obesity in students with intellectual disability in Jakarta. Medical Journal of Indonesia, 23(2), 106-111. https://doi.org/10.13181/mji.v23i2.688

Weatherspoon, D. L., Phillips, K., \& Wyatt, T. H. (2015). Effect of Electronic Interactive Simulation on Senior Bachelor of Science in Nursing Students' Critical Thinking and Clinical Judgment Skills. Clinical Simulation in Nursing, 11(2), 126-133. https://doi.org/10.1016/j.ecns.2014.11.006

World Health Organization ( 2016 ), Disability and Health. 